\title{
A comprehensive study of grape pomace extract and its active components as effective vapour phase corrosion inhibitor of mild steel
}

\author{
V. Vorobyova, ${ }^{1} *$ O. Chygyrynets', ${ }^{1}$ M. Skiba, ${ }^{2}$ T. Zhuk, ${ }^{1}$ I. Kurmakova ${ }^{3}$ \\ and O. Bondar ${ }^{3}$ \\ ${ }^{I}$ National Technical University of Ukraine "Igor Sikorsky Kyiv Polytechnic Institute”, Ave \\ Peremogy 37, Kiev, 03056 Ukraine \\ ${ }^{2}$ Ukrainian State Chemical-Engineering University, Gagarin Ave. 8, Dnipro, \\ 49005 Ukraine \\ ${ }^{3}$ Chernihiv National T.G. Shevchenko Pedagogical University, 53 Hetmana Polubotka str., \\ 14013 Chernihiv, Ukraine \\ *E-mail: vorobyovavika1988@gmail.com
}

\begin{abstract}
The inhibition efficiency of grape pomace extract (GPE) and its main constituents (2phenylacetaldehyde, hexanal) as a green volatile corrosion inhibitor for the temporary protection of mild steel was investigated. Weight loss measurements and potentiodynamic polarization techniques were all used for this assessment. The major constituents of GPE were identified by GC-MS analysis. Grape pomace extract inhibited mild steel corrosion under conditions of periodic condensation of moisture with a protection efficiency of $\sim 92 \%$. The gravimetric measurement indicates that inhibition efficiency shows direct proportional relation with concentration of inhibitor. The corrosion rate reduction is time dependent, and the highest protection values were achieved only in $48 \mathrm{~h}$. Inhibition efficiency increases in the order: grape pomace extract $>2$-phenylacetaldehyde $>$ hexanal. The grape pomace extract and main components acted as a mixed-type inhibitor with predominant cathodic effectiveness. Structural characterization by using SEM, AFM images and FT-IR analysis further supported the electrochemical and weight loss measurements results obtained.

Received: February 2, 2018. Published: May 16, 2018

doi: $\underline{10.17675 / 2305-6894-2018-7-2-6}$
\end{abstract}

Key words: atmospheric corrosion, grape pomace, volatile inhibitor, 2-phenylacetaldehyde, hexanal.

\section{Introduction}

During the past decades, a great number of synthetic compounds have been reported as effective inhibitors for the protection steel of atmospheric corrosion. Among them, the use of vapor phase inhibitors (VCI) is an effective and convenient means [1-8]. However for 
the reason of their expensiveness and increasing awareness of health and ecological risks, attention is being drawn towards finding highly efficient, cheap and non-toxic inhibitors.

Over the recent years, the use of naturally occurring substances of plant origin, otherwise called "green corrosion inhibitors" has received much more attention because they are incredible sources of natural organic compounds, which are environmentally acceptable, inexpensive, readily available and renewable sources of materials [9-13].

As one of these sources, we can use products of grapes processing - pomaces (from the Vitis vinifera family). Grape pomace is an industrial waste from the wine process and it consists of grape seeds, skin and stems [14]. The successful utilization of this natural waste may also provide an option for resource recovery. The pomace of grapes, which contain many chemical compounds, can be used as VCI. In the literature, one can also find no information about possible applications of the grape pomace and its extracted compounds for the development of VCI. Some works have investigated corrosion inhibition of grape pomace extract on steel in acidic solutions; however, the constituents that provide inhibitive action, the mechanisms and the best condition for inhibition are still unclear. Although, there are numerous successful reports on plant extracts can be found used as corrosion inhibitors, the phytochemical investigation of the extract is rarely carried out and research are seldom made on the pure compounds present in the plant extract [15-18]. Noticeably, the plant extract is a mixture of various components, which results in the complex inhibitive mechanism. It is rather difficult to determine what components present in plant extract create their relatively high ability to inhibit corrosion. A better way is to isolate the components and investigate the inhibition of each single component, but it is still difficult to isolate all the components. Thus, testing the inhibition potential of major components using available pure compounds could be an alternative choice to explore the corrosion inhibition of plant extract.

The aim of the present work is to evaluate the corrosion inhibition effect of grape pomace extract (GPE) as green vapour phase corrosion inhibitor of mild steel and also investigated the constituents that provide inhibitive action of the extract. For this purpose, the compounds were identified and quantified by GC-MS analysis. The corrosion inhibition efficiency of the grape pomace extract and of main compounds (2-phenylacetaldehyde, hexanal) was characterized by using electrochemical methods and was compared to their inhibition activity evaluated by the method of accelerated tests under simulated operational conditions. The electro-chemical behavior analysis and microscopic surface observation softer immersion in the corrosive medium were combined to discuss the role of the main molecules in the corrosion protection brought by the extract.

\section{Experimental}

\section{Materials and Apparatus}

The corrosion test and electrochemical measurements were carried out using mild steel strips. The composition of the mild steel is given in \%: C 0.21; Mn 0.05; P 0.09; S 0.05; $\mathrm{Al}$ 
0.01 ; P 0.02 ; balance Fe. The exposed area was mechanically abraded with $220,400,800$ and 1000 grades of emery papers, degreased with acetone and rinsed by distilled water before each electrochemical experiment.

\section{Preparation and characterization of the grape pomace extract}

The organic solvent 2-propanol was applied for soxhlet extraction. Grape pomace samples $(5.0 \mathrm{~g})$ were placed inside a thimble made of thick filter paper, loaded into the main chamber of the soxhlet extractor, which consisted of an extracting tube, a glass balloon and a condenser. The total extracting time was $6 \mathrm{~h}$, with the solvent continuously refluxing over the sample (grape pomace).

The composition of volatile substances of the extract was studied by means of method of chromatography-and-mass spectrometry methods, using a FINIGAN FOCUS gas chromatograph. About $10 \mu \mathrm{l}$ of the grape pomace extract sonicated with $n$-hexane were analyzed by GC-MS using Shimadzu Model GC-17A equipped with a flame ionization detection (FID) and a CBP-5 capillary fused silica column $(25 \mathrm{~m}, 0.25 \mathrm{~mm}$ i.d., $0.22 \mathrm{~mm}$ film thickness). The oven temperature was held at $50^{\circ} \mathrm{C}$ for 2 min then programmed at $10^{\circ} \mathrm{C} / \mathrm{min}$ to $250^{\circ} \mathrm{C}$, held for $20 \mathrm{~min}$. Other operating conditions were following: carrier gas, He (99.99\%), inlet pressure $76 \mathrm{kPa}$, with a linear velocity of $20 \mathrm{~cm} / \mathrm{s}$; injector temperature, $250^{\circ} \mathrm{C}$; detector temperature, $310^{\circ} \mathrm{C}$; split ratio, $1: 25$. The components were identified by comparing the peak retention times in the chromatogram and the complete mass-spectra of individual components with the corresponding results for pure compounds in the NIST-5 Mass Spectral Library.

FT-IR analysis was carried out by Bruker Tensor 27 FT-IR spectrometer in attenuated total reflection mode (Pike Technologies, GladiATR for FTIR with diamond crystal) and using spectral range of $4000-400 \mathrm{~cm}^{-1}$ with resolution of $4 \mathrm{~cm}^{-1}$.

\section{Gravimetric measurements}

Inhibitor effectiveness of the grape pomace extract as a vapor phase inhibitor of atmospheric corrosion of steel was evaluated with the method of accelerated tests under condition of condensation of moisture. The final geometrical area was $25 \mathrm{~cm}^{2}$. The gravimetric measurement was conducted by suspending the samples in a $250 \mathrm{~cm}^{3}$ conical flask with a tight-fitting rubber cork containing a small dish. The VCI were placed in the dish $(2 \mathrm{ml})$ for a certain period of time (depending on the experiment, from 24 to 72 hours) to form a protective film. After inhibitor film-forming period, $15 \mathrm{~cm}^{3}$ of deionized water were added. The test process included cyclic warming and cooling of the samples in a corrosion testing chamber with varying humidity. One cycle included an $8 \mathrm{~h}$ exposure in the thermostat $\left(40 \pm 1{ }^{\circ} \mathrm{C}\right)$, and a $16 \mathrm{~h}$ exposure at room temperature $\left.25^{\circ} \mathrm{C}\right)$. The total duration of the tests was 21 days. To prove reproducibility, gravimetric measurements were repeated twice. 


\section{Electrochemical measurements}

Electrochemical measurements were conducted in simulated atmospheric corrosion solution. The latter was prepared using double-distilled water which contained $7.1 \mathrm{~g} / \mathrm{L}$ $\mathrm{Na}_{2} \mathrm{SO}_{4}$. Electrochemical experiments were carried out in a conventional three-electrode cell with a platinum counter electrode (CE) and a saturated calomel electrode (SCE) coupled to a fine Luggin capillary as the reference electrode. To minimize the ohmic contribution, the tip of Luggin capillary was kept close to working electrode (WE). The carbon steel working electrode was designed with a fixed exposed surface area of 0.385 $\mathrm{cm}^{2}$. As a specific feature of our electrochemical investigations, we can mention the following fact: the disk-shaped surface of the end face of the working electrode was immersed in surface layers of the working solution by at most $1-2 \mathrm{~mm}$.

Electrochemical impedance spectroscopy was measured at open circuit potential with a $10 \mathrm{mV}$ AC perturbation with frequency ranging from $100 \mathrm{kHz}$ to $0.05 \mathrm{mHz}$ with 10 points per decade. The test device and the cell configuration for EIS measurements were the same as those for the polarization tests. To prove reproducibility, the polarization tests and EIS measurements were repeated three times.

\section{Characterization of the inhibition film by SEM and AFM}

The surface morphology and coating were examined by FEI E-SEM XL 30 (Detection of secondary electrons). For SEM images, a $1 \mathrm{~cm}^{2}$ sample were taken.

Surface analysis was carried out by AFM technique in order to evaluate the surface morphology of the steel samples after 48 hours of film-forming in the vapor phase of inhibitors. Samples of dimension $1.0 \mathrm{~cm} \times 1.0 \mathrm{~cm} \times 0.06 \mathrm{~cm}$ were abraded with emery paper (grade 320-500-800) and then washed with distilled water and acetone. The surface morphology and coating were analyzed with the help of SPA-400 SPM unit atomic force microscope (AFM).

\section{Quantum chemical calculations}

The computational study was performed to understand the inhibitive activity trend of various molecules present in the inhibitor using HyperChem 7 program package. The two inhibitor molecules are shown in Table 1. The geometry optimization was performed by application of the restricted Hartree-Fock method (RHF) using MNDO approach with PM3 parameterization. The molecular properties that were calculated include the energy of the highest occupied molecular orbital (HOMO), the energy of the lowest unoccupied molecular orbital (LUMO), the energy gap $(\Delta \varepsilon)$, electronegativity $(\chi)$, hardness $(\eta)$, electrophilicity index $(\omega)$, electron charge transfer $(\Delta N)$ and energy change $(\Delta E)[19,20]$. 


\section{Results and discussion}

\section{Volatile components of grape pomace extract}

In the volatile fraction of the grape pomace extract 22 compounds were detected by the chromatography-and-mass spectrometry method (Figure 1, Table 1). This result indicates that grape pomace extracts contain various classes of organic substances that can act as corrosion inhibitors. According to the chromatogram, nine aldehydes are identified by GCMS in the grape pomace extract, namely, hexanal (9.1\%), heptanal (8.7\%), 2phenylacetaldehyde $(6.5 \%)$, butanal $(4.8 \%)$, nonanal $(7.0 \%)$, (2E)-3,7-dimethyl-2,6octadien-1-ol (2.3\%), 4-hydroxy-3-methoxybenzaldehyde, terpenes, saturated and unsaturated fat acids (34\%) represented by hexadecanoic acid (5.4\%), (9Z)-octadec-9-enoic acid $(6.1 \%)$, and $(9 Z, 12 Z)-9,12$-octadecadienoic acid $(4.2 \%)$. The results of the weight ratio determination are given in Table 1 and show that, among the identified aldehydes, the major compounds are hexanal, heptanal, 2-phenylacetaldehyde, butanal, and nonanal. The aim of this part is to compare the inhibition provided by grape pomace extract constituents in order to find the main constituent responsible for corrosion inhibition properties of the plant extract. Therefore, for inhibition characterizations the main compounds, namely 2phenylacetaldehyde and hexanal, were chosen as representative molecules of the grape pomace extract. The chemical formulas of the chosen inhibiting molecules are given in Table 2.

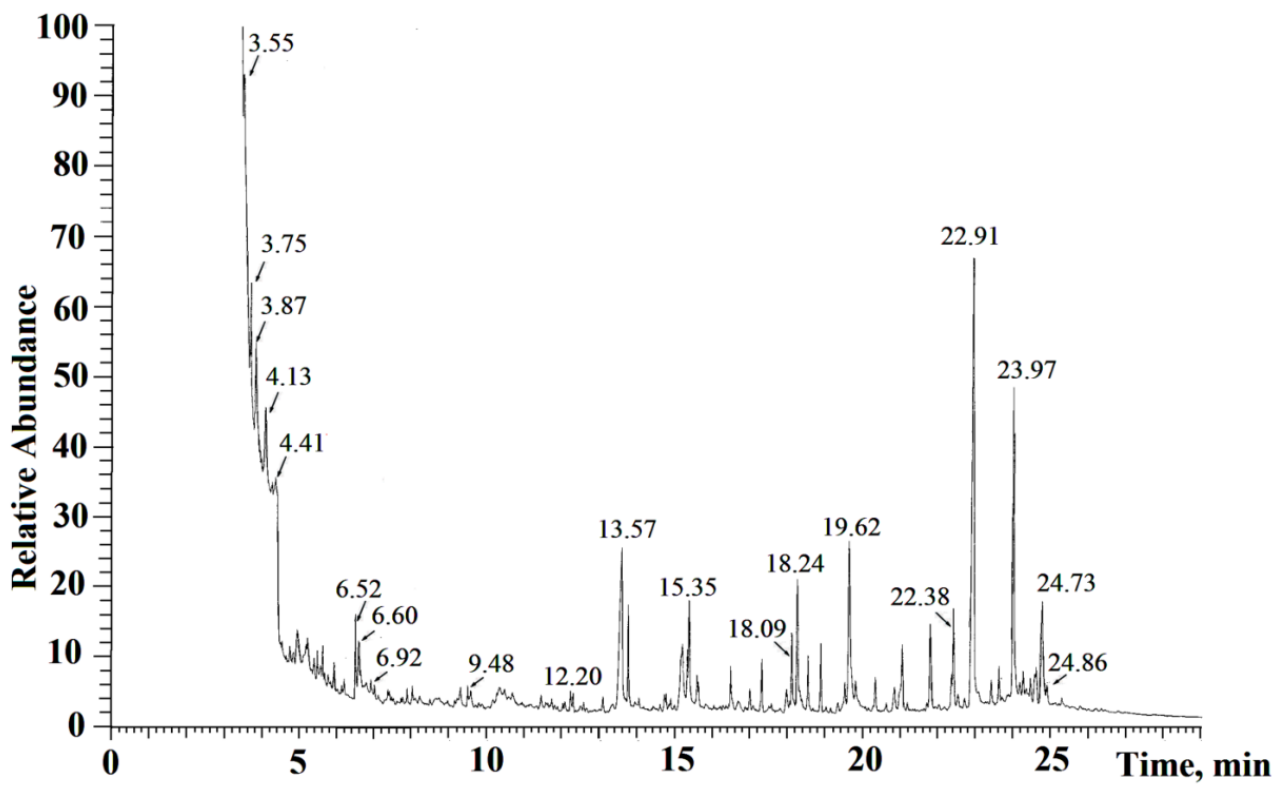

Figure 1. GC-MS profile of volatile components of grape pomace extract. 
Table 1. Results of GPE analysis by GC-MS.

\begin{tabular}{|c|c|c|}
\hline Name of compound & $\begin{array}{l}\text { Holding time } t, \\
\text { min }\end{array}$ & Weight ratio, $\%$ \\
\hline Hexanal & 3.55 & 9.1 \\
\hline Heptanal & 3.75 & 8.7 \\
\hline 2-Phenylacetaldehyde & 3.87 & 6.5 \\
\hline Butanal (Butyraldehyde) & 4.13 & 4.8 \\
\hline Nonanal & 4.41 & 7.0 \\
\hline (2E)-3,7-Dimethyl-2,6-octadien-1-ol & 6.52 & 2.3 \\
\hline Propane-1,2,3-triol (Glycerol) & 6.60 & 0.9 \\
\hline 4-Hydroxy-3,5-dimethoxybenzaldehyde (Syringaldehyde) & 6.92 & 1.1 \\
\hline (2E)-3-Phenylprop-2-enal (Cinnamaldehyde) & 9.48 & 0.9 \\
\hline 4-Hydroxy-3-methoxybenzaldehyde (Vanillin) & 12.20 & 1.1 \\
\hline 2-Methyl-2-propanyl-4-hydroxy-4-methyl-5-hexanoate & 13.57 & 4.8 \\
\hline Heptacosane & 17.31 & 3.2 \\
\hline (9Z,12Z)-9,12-Octadecadienoic acid (Linoleic acid) & 18.09 & 4.2 \\
\hline Hexadecanoic acid (Palmitic acid) & 18.24 & 5.4 \\
\hline (9Z)-Octadec-9-enoic acid (Oleic acid) & 19.62 & 6.1 \\
\hline $\begin{array}{l}\text { (1R,4E,9S)-4,11,11-Trimethyl-8-methylidene- } \\
\text { bicyclo[7.2.0]undec-4-ene (Caryophyllene) }\end{array}$ & 21.01 & 1.7 \\
\hline (Naphthalene-1-yl)(1-pentyl-1H-indol-3-yl)methanone & 22.86 & 6.2 \\
\hline 2-(4-Methyl-1-cyclohex-3-enyl)propan-2-ol ( $\alpha$-Terpineol) & 23.94 & 9.5 \\
\hline $\begin{array}{l}\text { 1-Methyl-4-(1-methylethylidene)cyclohexan-1-ol ( } \gamma \text { - } \\
\text { Terpineol) }\end{array}$ & 24.01 & 4.2 \\
\hline $\begin{array}{c}(1 R, 3 \mathrm{a} R, 5 \mathrm{a} R, 5 \mathrm{~b} R, 7 \mathrm{a} R, 9 S, 11 \mathrm{a} R, 11 \mathrm{~b} R, 13 \mathrm{a} R, 13 \mathrm{~b} R)- \\
\text { 3a,5a,5b,8,8,11a-hexamethyl-1-prop-1-en-2-yl-} \\
\text { 1,2,3,4,5,6,7,7a,9,10,11,11b,12,13,13a,13b- } \\
\text { hexadecahydrocyclopenta[a]chrysen-9-ol (Lupeol) }\end{array}$ & 24.52 & 9.5 \\
\hline Lup-20(29)-ene-3ß,28-diol (Betulin) & 27.41 & 3.8 \\
\hline
\end{tabular}

Table 2. Chemical formulae of compounds tested as corrosion inhibitors.

\section{2-Phenylacetaldehyde}<smiles>O=CCc1ccccc1</smiles>

\section{Hexanal}

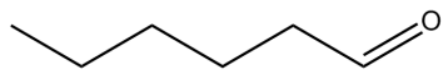


Weight loss measurements

Effect of pomaces the grapes extract and main compounds on corrosion rate and inhibition efficiency

Figure 2 represents inhibition efficiency values obtained from the weight loss in conditions of periodic condensation of moisture after period of film-forming in the presence of different concentrations of grape pomace extract and major components. Clearly, inhibition efficiency increases with an increase of the inhibitor concentration, i.e. the corrosion inhibition enhances with the inhibitor concentration. This behavior is explained with the fact that the adsorption amount and coverage of inhibitor on steel surface increases with the inhibitor concentration.

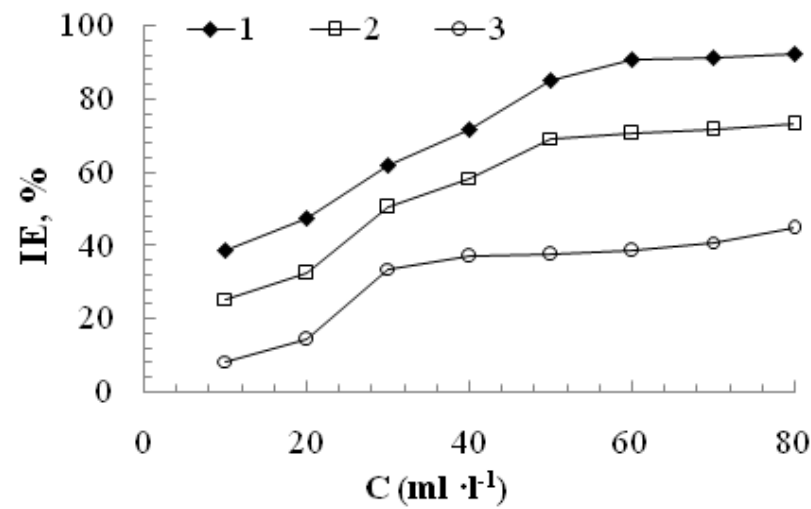

Figure 2. Relationship between inhibition efficiency and concentration of inhibitor $(C)(1-$ Grape pomace extract, 2 - 2-phenylacetaldehyde, 3 - hexanal) under conditions of periodic moisture condensation for 21 days (weight loss method, pre-treatment immersion time $48 \mathrm{~h}$ ).

At $80 \mathrm{mg}^{-1}$, the maximum IE is $92.08 \%$ for grape pomace extract; $72.24 \%$ for 2 phenylacetaldehyde; $44.6 \%$ for hexanal, which indicates all compounds act as moderate corrosion inhibitors for steel. Figure 2 also shows that the values of inhibition efficiency follow the order: grapes pomace extract $>2$-phenylacetaldehyde $>$ hexanal. This result implies that the grape pomace extract exhibits better inhibition performance than its major components. Similar comparative results between plant extract and its major component have also been reported for the coffee extract [19] and Artemisia pallens [18].

The influence of pre-treatment immersion time of steel in the volatile phase of the GPE on corrosion effect under the conditions of periodic moisture condensation was investigated. It should be noted that the corrosion rate decreases with increasing the filmformation time.

The inhibition efficiency (IE) increases in the range 65.32-96.39\%. The inhibition efficiency after $72 \mathrm{~h}$ of GPE film-forming was higher than that after 12 and $46 \mathrm{~h}$ of GPE film-forming (Figure 3). This suggested that the corrosion protectiveness of GPE filmforming on the steel surface was enhanced by prolonging the GPE treatment. The 
protective film on the steel surface is formed for $40-48 \mathrm{~h}$ of its treatment with volatile compounds of the extract. The effect of immersion time in the vapor phase of extract on the weight loss rate indicated that GPE not only keeps its inhibitive activity for steel, but also improves its effectiveness over the long term immersion due to synergistic influence of the main compounds which offer an additional protection. It should be noted that the treatment of specimens in the vapor phase of individual 2-propanol does not improve the corrosion resistance of the metal. This enables us to recommend this extract for the corrosion protection of mild steel.

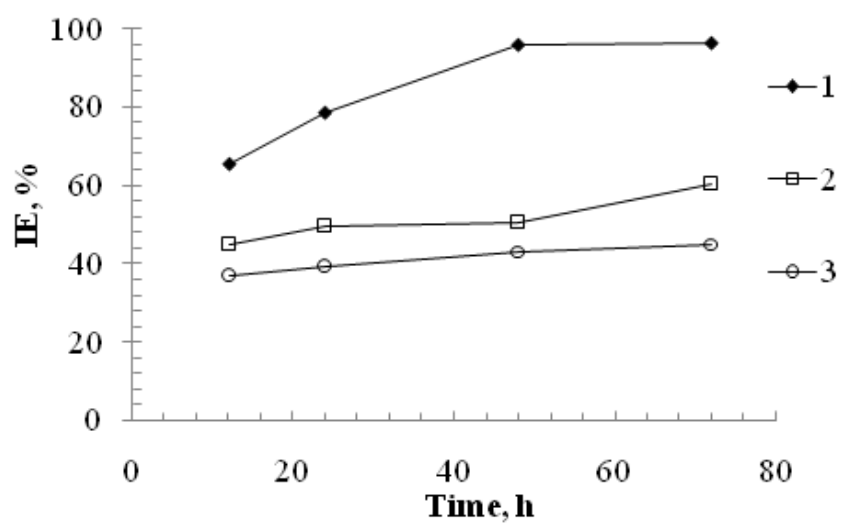

Figure 3. Relationship between inhibition efficiency and pre-treatment immersion time of St3 in vapor phase of inhibitor ( 1 - Grape pomace extract, 2 - 2-phenylacetaldehyde, 3 hexanal).

\section{Potentiodynamic curves}

Polarization measurements were performed to monitor the mechanism of anodic and cathodic partial reactions and to identify the effect of an inhibitor on each partial reaction (Figures 4-6). From the potentiodynamic polarisation curves, it can be seen that the extract and basic compounds caused a decrease in both anodic and cathodic current densities, most likely due to the adsorption of the organic compounds present in the extracts at the active sites of the electrode surface. Both the cathodic slopes and the anodic slopes do not change obviously, which indicates that the mechanism of the corrosion reaction does not change and the corrosion reaction is inhibited by a simple adsorption mode. The presence of protective film on the surface that formed in vapor phase of extract result marked shift in the cathodic branches and to a lesser extent in the anodic branches of the polarization curves. Moreover, in the presence of grape pomace extract the values of corrosion potential $E_{\text {corr }}$ are nearly constant; therefore, the GPE could be classified as a mixed-type inhibitor with predominant cathodic effectiveness. 


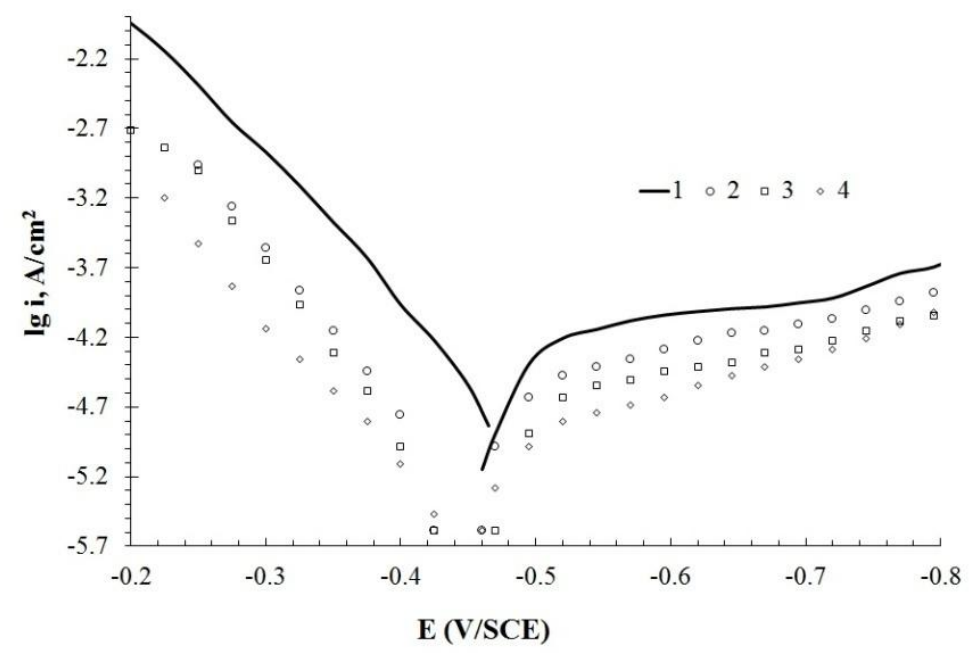

Figure 4. Potentiodynamic polarization curves of mild steel in $0.5 \mathrm{M} \mathrm{Na}_{2} \mathrm{SO}_{4}$ without (1) and with a film formed after 24 (2); 48 (3) and 72 (4) h in the vapor phase of GPE.

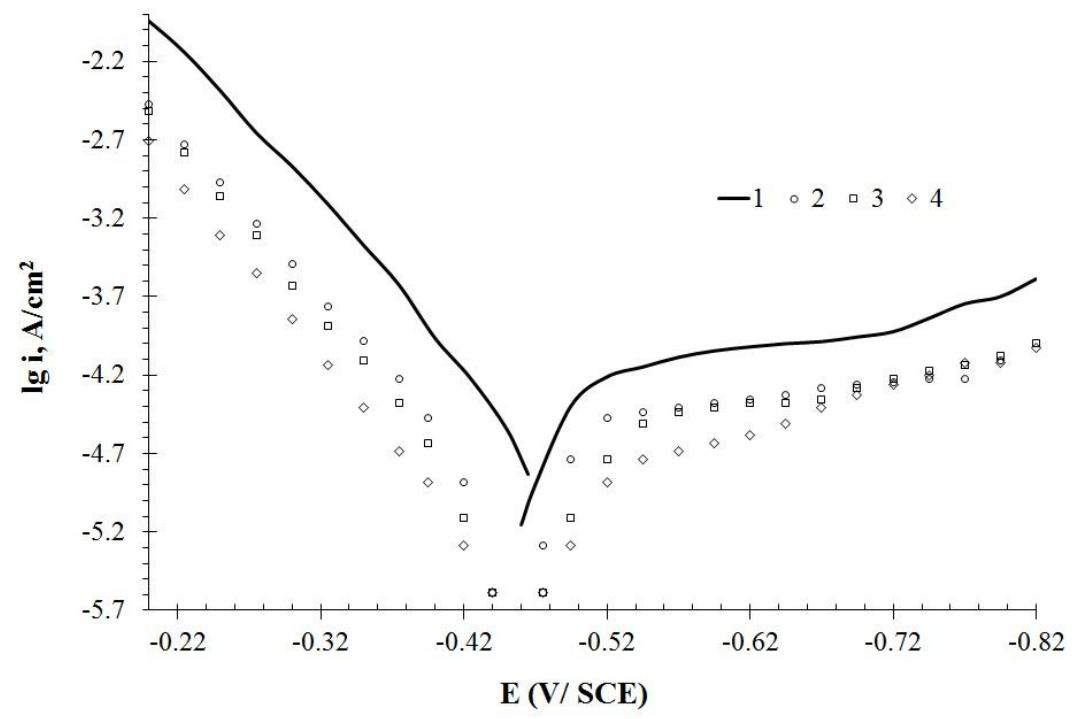

Figure 5. Potentiodynamic polarization curves of mild steel in $0.5 \mathrm{M} \mathrm{Na}_{2} \mathrm{SO}_{4}$ without (1) and with a film formed after 24 (2); 48 (3) and 72 (4) $\mathrm{h}$ in the vapor phase of 2-phenylacetaldehyde.

The inhibitive action for these constituents increases in the following order: GPE > 2phenylacetaldehyde > hexanal.

This order reflects the important role played by the 2-phenylacetaldehyde molecules. It has the highest inhibition efficiency among the other constituents.

Figure 7 represents the Nyquist diagrams for steel in $1 \mathrm{~N} \mathrm{Na}_{2} \mathrm{SO}_{4}$ without protective film (curve 1) and with a film formed after holding for $48 \mathrm{~h}$ in the vapor phase of GPE (curve 2). The most common equivalent circuit used to model corrosion of bare metal in aqueous electrolyte is the Randles circuit, shown in Figure 8. 


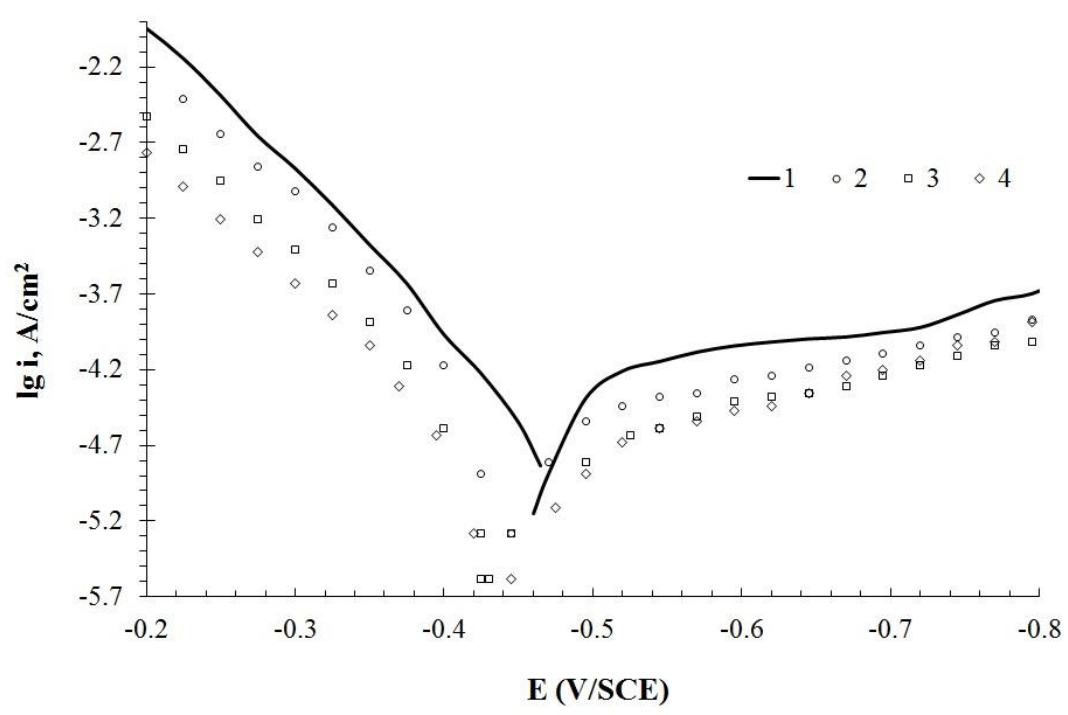

Figure 6. Potentiodynamic polarization curves of mild steel in $0.5 \mathrm{M} \mathrm{Na}_{2} \mathrm{SO}_{4}$ without (1) and with a film formed after 24 (2); 48 (3) and 72 (4) $\mathrm{h}$ in the vapor phase of hexanal.

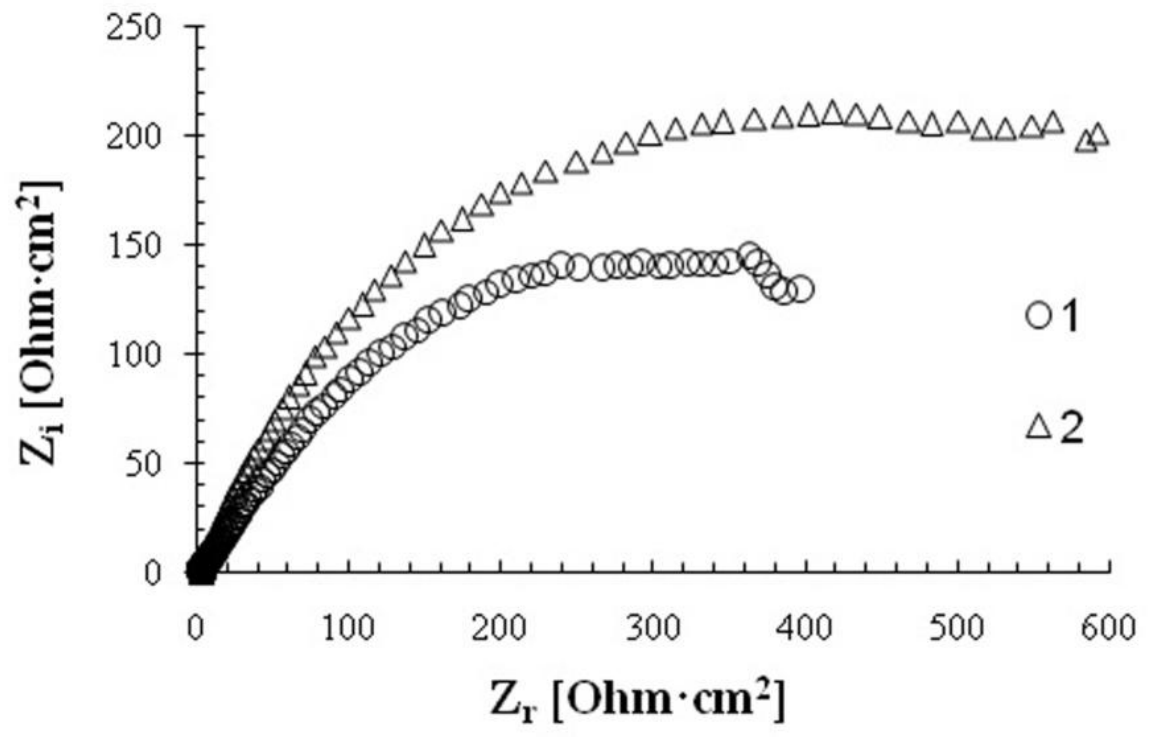

Figure 7. Nyquist plots measured at $E_{\text {corr }}$ for St3 steel in $1 \mathrm{~N} \mathrm{Na}_{2} \mathrm{SO}_{4}$ without protective film (curve 1) and with a film formed after holding for $48 \mathrm{~h}$ in the vapor phase of the volatile compounds of GPE. 


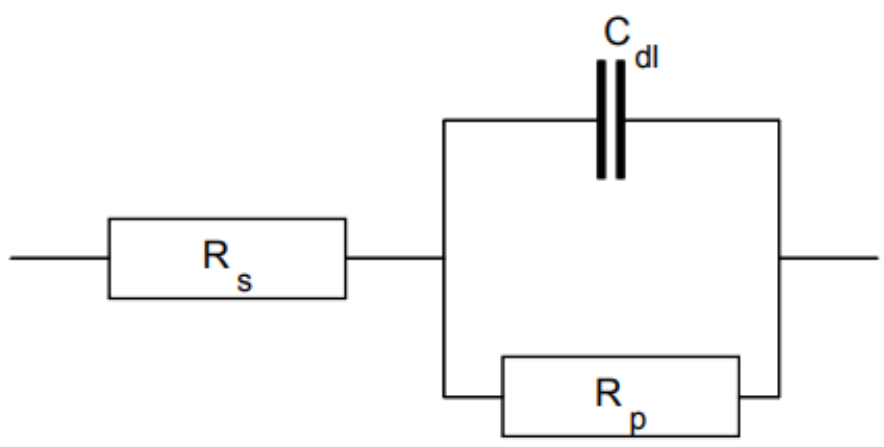

Figure 8. Equivalent electrical circuit used for computer fitting of the experimental data.

The Nyquist diagram of steel in the absence of protective film describes a capacitive arc with high frequency values, which is followed by a straight line at lower frequency values (Table 3). In the presence of protective film, the impedance spectrum switches to double-capacitive semicircles. The disappearance of the diffusion features in the presence of protective film indicates that the corrosion reaction is inhibited by protective film, which makes the diffusion process no longer the control process. Furthermore, the inhibition efficiencies obtained from weight loss and polarization curves are in reasonably good agreement.

Table 3. Typical parameters obtained from EIS fitting results of St3 steel in $1 \mathrm{~N} \mathrm{Na}_{2} \mathrm{SO}_{4}$ without protective film and with a film formed after holding for $48 \mathrm{~h}$ in the vapor phase of GPE.

\begin{tabular}{ccccc}
\cline { 2 - 5 } Sample & $\boldsymbol{R}_{\mathbf{1}} \mathbf{, ~} \mathbf{O h m} \cdot \mathbf{c m}^{\mathbf{2}}$ & $\boldsymbol{R}_{\mathbf{2}} \mathbf{, ~} \mathbf{O h m} \cdot \mathbf{c m}^{\mathbf{2}}$ & $\boldsymbol{C P E}_{\mathbf{1}}, \boldsymbol{\mu F} \cdot \mathbf{c m}^{\mathbf{2}}$ & $\boldsymbol{W}^{*}, \mathbf{O h m} \cdot \mathbf{c m}^{\mathbf{2}}$ \\
\hline Without protective films & 3.76 & 586 & 26 & - \\
With protective films & 3.97 & 812 & 20 & - \\
\hline
\end{tabular}

$* W$ - Warburg resistance which is related to diffusion limitation (resistance of electrolyte in pores).

The results obtained from weight loss and potentiodynamic polarization are in good agreement, and the compounds inhibition action could also be evidenced by surface SEM and AFM images.

Scanning electron microscope (SEM) surface examination

SEM analyses were conducted in order to characterize the protective layer that formed on the low carbon steel surface. SEM images of initial surface and surface after 48 hours of film-forming are shown in Figures 9-11. The surface morphology of the sample before exposure to volatiles of extract and two compounds indicates there were a few scratches from the mechanical polishing treatment (Figure 9a). This image displays a freshly polished steel surface. The following images (Figure $9 \mathrm{~b}$ ) are of the steel surface after $48 \mathrm{~h}$ 
of exposure for the film-forming of the grapes pomace extract. It shows a thin film which covers the surface. As shown in Figure 9b, the steel sample appeared to be smooth and without any visible traces of corrosion products, due to the formation of a protective inhibitor layer on the metallic surface, which retarded the dissolution process. Presumably, the inhibitory effect was performed via the adsorption of compounds present in the grape pomace extract onto the steel surface. The steel surface after $48 \mathrm{~h}$ exposition for the filmforming in the vapour phase of 2-phenylacetaldehyde and grape pomace extract had the typical structures. (Figure 10a,b). A totally different situation was observed after 48 hours of film-forming in the vapor phase of hexanal (Figure 11). The steel surface after $48 \mathrm{~h}$ of film-forming in vapour phase of 2-phenylacetaldehyde was slightly rougher than that after forming film in volatile compounds of hexanal. The particles are less distributed and rather uniform, and the outer surface of the particles is enwrapped with tightly and regularly.
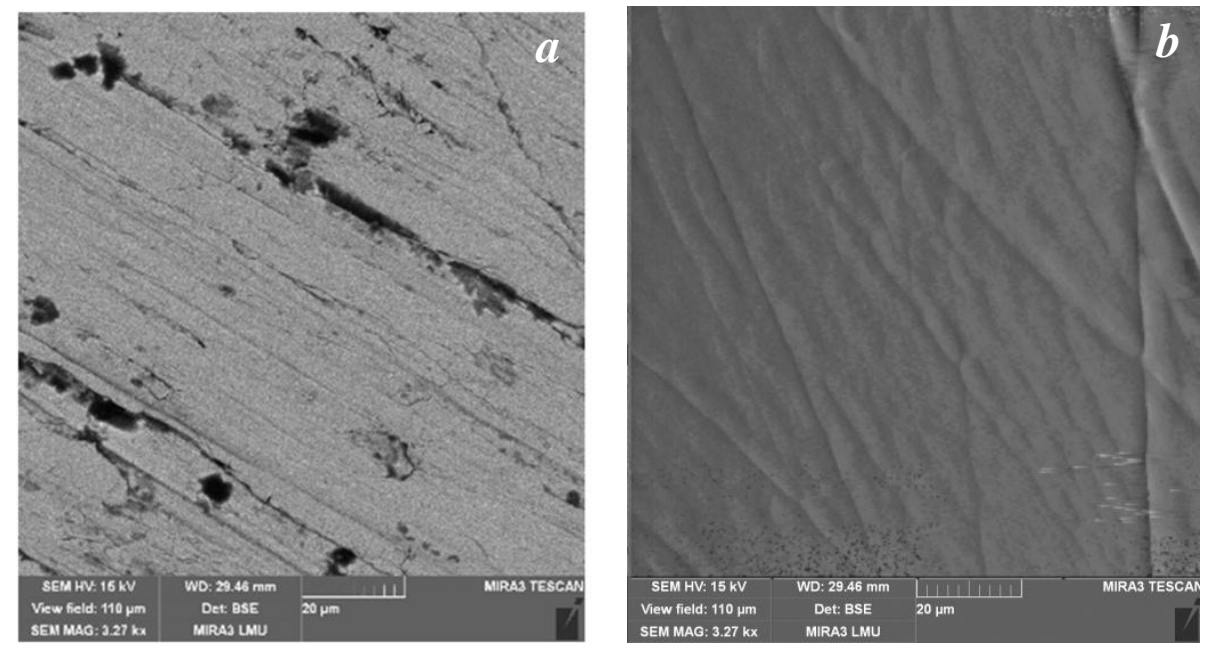

Figure 9. SEM images of the carbon steel surface: (a) initial surface; after $48 \mathrm{~h}$ exposure for GPE film-forming (b).
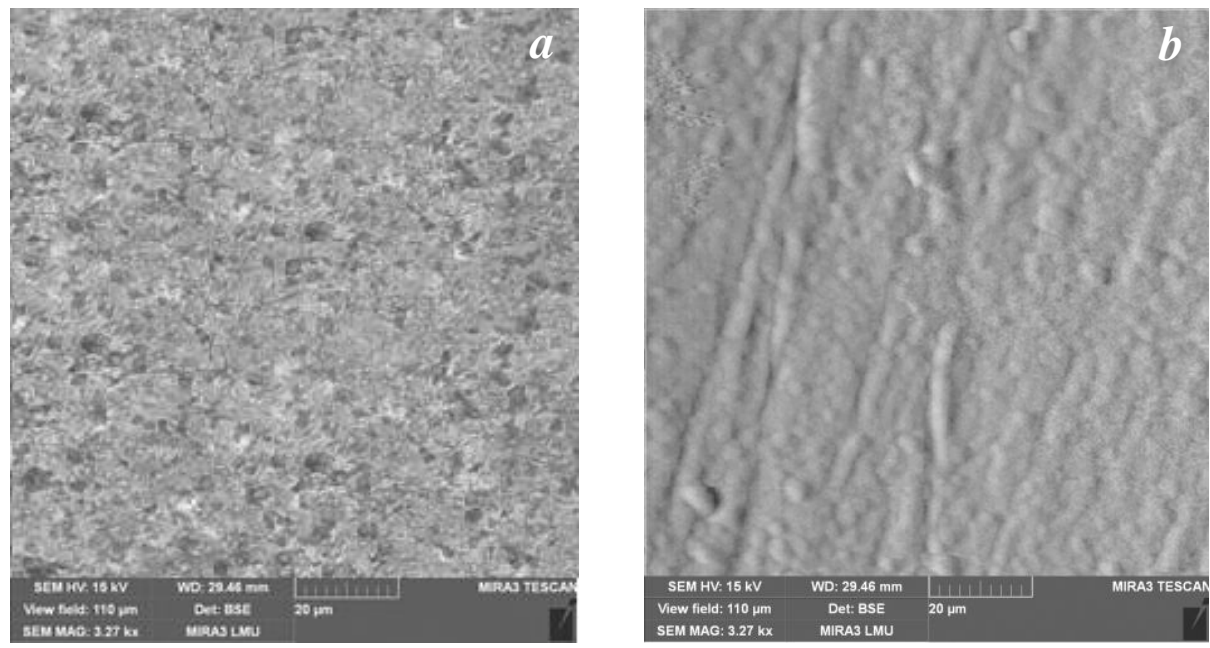

Figure 10. SEM images of the carbon steel surface after $24 \mathrm{~h}$ (a) and $48 \mathrm{~h}$ (b) exposure for 2phenylacetaldehyde film-forming. 


\section{Atomic force microscope (AFM) surface examination}

The atomic force microscope provides a powerful means of characterizing the microstructure. The two-dimensional AFM image of steel surface before exposure to volatiles of extract is shown in Figure 12a.
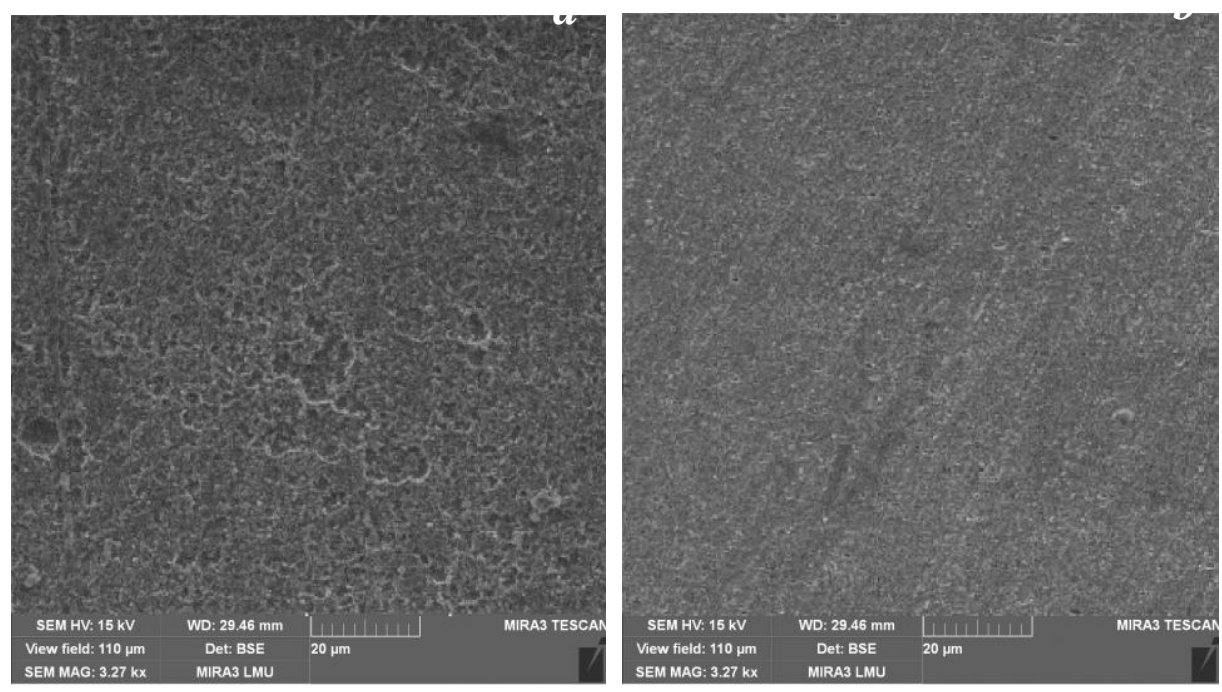

Figure 11. SEM images of the carbon steel surface after $24 \mathrm{~h}$ (a) and $48 \mathrm{~h}$ (b) exposure for hexanal film-forming
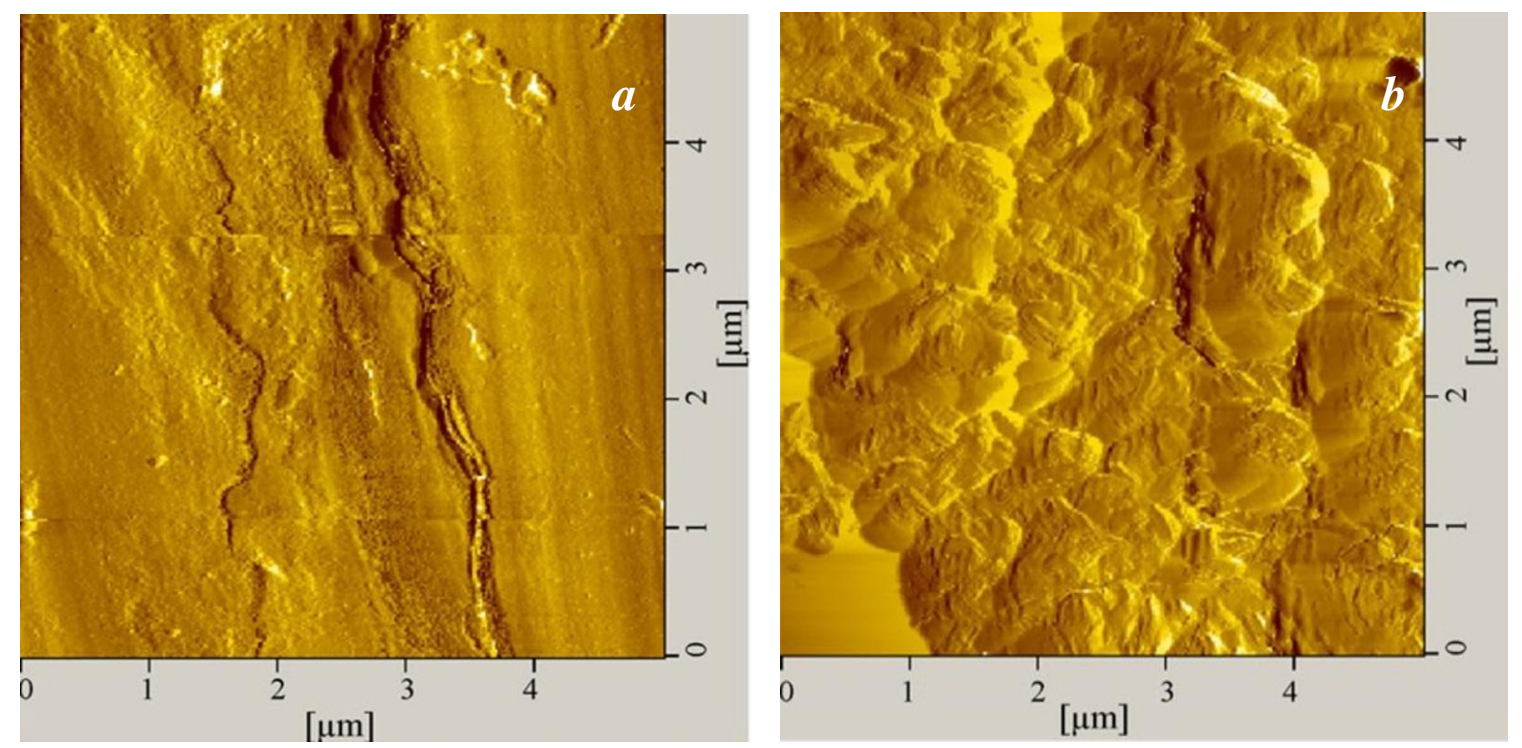

Figure 12. AFM two-dimensional images of the steel surface: (a) initial surface; (b) after $48 \mathrm{~h}$ exposure for GPE film-forming (b).

Figure $12 \mathrm{~b}$ shows the spherical or bread-like particles that appear on the surface, which do not exist in Figure 12a. Therefore, it may be concluded that these particles are the adsorption film of the inhibitor, which efficiently inhibits the corrosion of steel. Figure $12 b$ also shows that a uniform film was formed. The inhibition efficiency of grapes pomace 
extract is attributed to joint adsorption of some of its phytochemical constituents. Therefore, the use of 2-propanol GPE as an inhibitor for the corrosion of mild steel from corrosion under the conditions of periodic moisture condensation is recommended.

\section{FT-IR analysis}

Fourier-transformation infrared spectroscopy was used to identify the functional groups of components which are present in the grape pomace extract and were adsorbed onto surface of steel. FT-IR analysis of the carbon steel specimens in the absence and after the formation of a film for $72 \mathrm{~h}$ in the presence of extract was carried out between 600 and $4000 \mathrm{~cm}^{-1}$.

In the FT-IR spectrum of GPE presented in Figure 13, several characteristic absorption bands were identified, such as stretching vibrations of intermolecular associated hydroxyl groups, $v(\mathrm{O}-\mathrm{H})$ at $3368 \mathrm{~cm}^{-1}$, symmetrical and asymmetrical vibrations for alkyl units $v\left(\mathrm{CH}_{2}\right)$ at $2926 \mathrm{~cm}^{-1}$ and $2851 \mathrm{~cm}^{-1}$, vibrations for aromatic rings $v(\mathrm{C}=\mathrm{C})$ at $1514 \mathrm{~cm}^{-1}$ and phenol moiety $v(\mathrm{C}-\mathrm{OH})$ at $1147 \mathrm{~cm}^{-1}$. The band at $1640 \mathrm{~cm}^{-1}$ is assigned to conjugated $\mathrm{C}=\mathrm{O}$ stretching vibration. The absorption bands within the interval from 1750$1600 \mathrm{~cm}^{-1}$ are related to the stretching vibrations of carbonyl groups of aldehydes. The band at $1452 \mathrm{~cm}^{-1}$ can be attributed to $\mathrm{C}=\mathrm{C}-\mathrm{C}$ aromatic ring stretching. The obtained results indicate that after 72 hours (Figure 13), the formation of the film on the IR spectra shows a decrease in the intensity of the oscillation in the region of $1700-1580 \mathrm{~cm}^{-1}$. The new band at $1690 \mathrm{~cm}^{-1}$ appeared is characteristic of $v(\mathrm{C}=\mathrm{C})$ groups maybe corresponding to new groups of compounds. This indicates the possible chemical change of the main compounds of GPE once adsorbed on the mild steel surface and explains the highest protection values that achieved only in $48 \mathrm{~h}$.

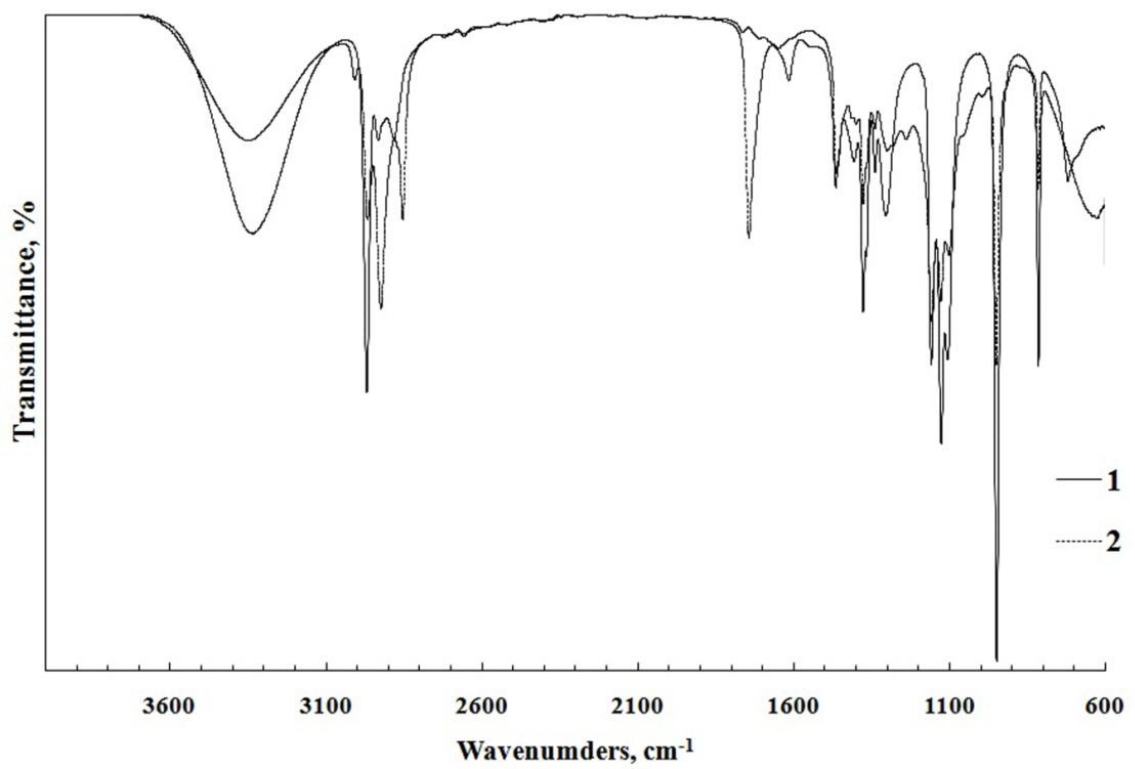

Figure 13. FT-IR absorption of 2-propanol GPE (1) and spectra displayed on the surface of Steel 3, treated in volatile compounds of the grapes pomaces extract (2). 


\section{Quantum chemical calculations}

In recent years, theoretical quantum chemical calculation was used to predict the adsorption center and explain the mechanism of corrosion inhibition effects. It is a useful method to investigate the mechanisms of reaction by calculating the structure and electronic parameters, which can be obtained by means of theoretical quantum theory [19, 20]. In chemical model of adsorption a chemical bond is presumed to be formed as a result of the donation of electrons from the filled HOMO of the inhibitor molecules to the vacant $\mathrm{d}$-orbitals of the metal. It is also possible that back bonding can result through electron donation by the filled metal d-orbitals to the vacant LUMO of the inhibitor.

Thus, the adsorption power of the hexanal and 2-phenylacetaldehyde molecules was studied using quantum chemical concepts and the density functional theory in order to identify the geometrical and electronic structures of the compounds.

The electric/orbital density distributions of HOMO and LUMO for hexanal and 2phenylacetaldehyde molecules are shown in Figure 14. It is found that the electron density of the frontier orbital is well proportioned. That is, there is electron transferring in the interaction between the inhibitor molecule and metal surface. The values of energy of highest occupied molecular orbital $\left(E_{\mathrm{HO} O}\right)$, energy of lowest unoccupied molecular orbital $\left(E_{\mathrm{LUMO}}\right)$ and the separation energy $\left(E_{\mathrm{LUMO}}-E_{\mathrm{HOMO}}, \Delta \varepsilon\right)$ are also presented in Table 4.

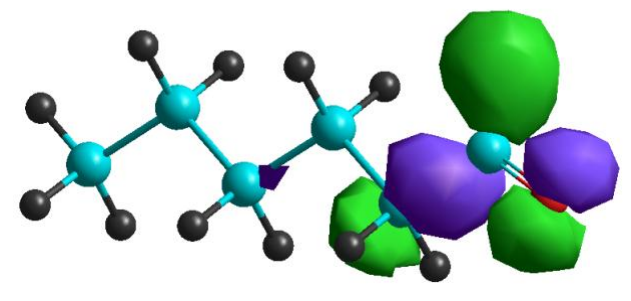

$a$

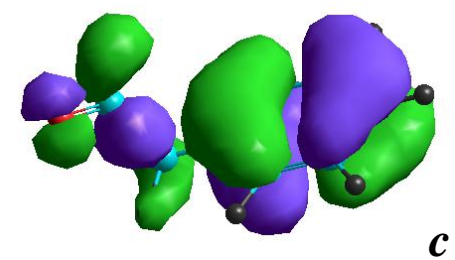

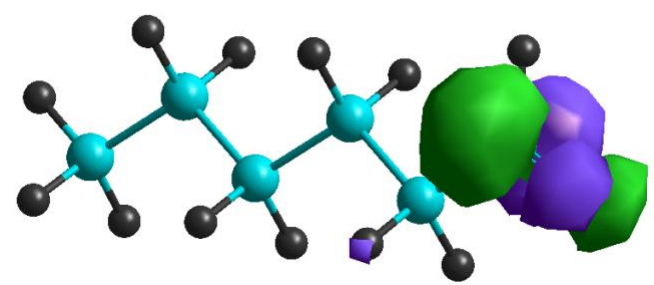

$b$

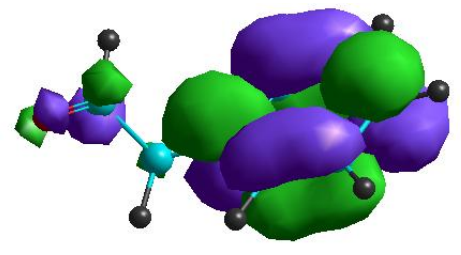

$d$

Figure 14. The frontier molecular orbital density distribution the main components of GPE using DFT: HOMO and LUMO of hexanal (a, b) and 2-phenylacetaldehyde (c, d).

From Table 4, $E_{\text {HOMO }}$ has almost no evident difference between hexanal and 2phenylacetaldehyde. On the other hand, $E_{\text {LUMO }}$ obeys the order: hexanal $<2$ phenylacetaldehyde, which is in a complete agreement with the inhibition efficiency order of 2-phenylacetaldehyde > hexanal. The energy gap $\Delta \varepsilon \mathrm{H}-\mathrm{L}(\mathrm{eV})$ value was also associated with the inhibition efficiency. A low value of $\Delta \varepsilon$, leads to higher inhibition efficiency because less energy will be required to remove the electron from last occupied orbital. The calculations from Table 4 show the following increasing reactivity abilities of the molecules towards steel: phenylacetaldehyde < hexane. 
Table 4. Calculated quantum chemical properties for the most stable conformations of the major effective components of extracts pomaces the grapes.

\begin{tabular}{cccc}
\hline Molecule & $\boldsymbol{E}_{\text {HOMO }}(\mathbf{e V})$ & $\boldsymbol{E}_{\text {LUMO }}(\mathbf{e V})$ & $\boldsymbol{\Delta}_{\mathrm{H}-\mathrm{L}}(\mathbf{e V})$ \\
\hline Hexanal & -10.771 & 0.864 & -11.63 \\
2-Phenylacetaldehyde & -9.908 & 0.125 & -10.03 \\
\hline
\end{tabular}

Corrosion inhibition of mild steel by organic inhibitors (present in plant extract) is a complex process and is mainly influenced by charge transport. Values of quantum chemical indices such as electronegativity $(\chi)$, hardness $(\eta)$, electrophilicity index $(\omega)$, electron charge transfer $(\Delta N)$ and energy change $(\Delta E)$ are associated with the electron charge transfer from molecule to steel surface (Table 5). The values of $\mu, \eta, \Delta N, \omega$ and $\Delta E$ are also listed in Table 5. According to some studies, the parameter of $\mu$ is related to the chemical potential, and higher value of $\mu$ means better inhibitive performance. Electrophilicity $(\omega)$ is an index which measures the propensity of chemical specie to accept electrons. Thus, a good nucleophile is characterized by low values of $\mu$ and $\omega$; whereas a good electrophile is characterized by high values of $\mu$ and $\omega$. It is clear in Table 4 that the molecules have low electrophilicity index values and are good nucleophiles. Values of $\Delta N$ exhibit inhibitive performance resulting from electron donations. If $\Delta N<3.6$, the inhibition efficiency increases with an increase in electron-donation ability to the metal surface. It can be seen from Table 5 that the values of $\Delta N$ between 2-phenylacetaldehyde and hexanal have evident difference.

Table 5. Quantum chemical parameters for inhibitor molecules and adsorption energies between the molecules and $\mathrm{Fe}(001)$ plane.

\begin{tabular}{cccccc}
\hline Molecule & $\boldsymbol{\mu}, \mathbf{e V}$ & $\eta, \mathbf{e V}$ & $\boldsymbol{\omega}$ & $\boldsymbol{\Delta N}$ & $\boldsymbol{\Delta} \boldsymbol{E}$ \\
\hline Hexanal & -4.95 & 5.81 & 1.238 & 0.175 & 0.00077 \\
2-Phenylacetaldehyde & -4.89 & 5.01 & 1.222 & 0.210 & 0.00025 \\
\hline
\end{tabular}

In the present study, inhibition efficiency follows the order: 2-phenylacetaldehyde > hexanal. Thus, there is a good correlation between inhibition efficiency and the parameters of $E_{\mathrm{LUMO}}, \Delta \varepsilon \mathrm{H}-\mathrm{L}$ and $\Delta N, \Delta E$. As shown by the quantum chemical calculations, the inhibition efficiency of the main compounds identified in the GPE depends on the molecule structure.

The molecules studied possess charge transfer abilities towards mild steel. In this study therefore, inhibitor molecules of GPE are the electron donors and the mild steel surface is an acceptor.

In addition, the theoretical inference is in good correspondence with experimental data. 


\section{Explanation for inhibition}

Grape pomace extract extract (GPE) is composed of numerous naturally occurring organic compounds. Accordingly, the inhibitive action of GPE could be attributed to the adsorption of its components on the steel surface. Owing to the complex chemical composition of the GPE, it is rather difficult to assign the inhibitive effective to a particular constituent. In the present study, the inhibition action of two major components 2-phenylacetaldehyde and hexanal are studied. The inhibitory properties of 2-phenylacetaldehyde are very similar to the extract, which implies that the aldehydes would be the major contributor to the activity. The effect of film forming period on the weight loss rate indicated that extract not only keeps its inhibitive activity for carbon steel under condition of condensation of moisture, but also improves its effectiveness over the long term test due to synergistic influence of the main compounds which offer an additional protection. According to the quantum chemical calculations, the adsorption of aldehydes is mainly through the $-\mathrm{CHO}$ functional group for aromatic aldehydes and $\mathrm{C}=\mathrm{C}$ functional group for unsaturated aldehydes. Noticeably, a number of aldehydes have similar chemical molecular structure, which implies that the series of aldehydes could be seemed as the potential contributors for the inhibition performance.

\section{Conclusions}

Grape pomace extract and two major compounds of 2-phenylacetaldehyde and hexanal act as moderate inhibitors of corrosion of mild steel exposed for the temporary protection of mild steel. Inhibition efficiency values follow the order: grape pomace extract $>2$ phenylacetaldehyde $>$ hexanal. Individual grape pomace extract, 2-phenylacetaldehyde and hexanal act as mixed-type inhibitors of corrosion. In this case, the rate of corrosion is controlled by the cathodic process of reduction of the molecular oxygen from air. It is shown that the inhibition of the atmospheric corrosion of steels after treatment in the vapor of volatile compounds the grapes pomace extract and two major compounds occurs due to the blocking of the metal surface by chemically adsorbed molecules. SEM and AFM results clearly show that GPE and two major compounds of 2-phenylacetaldehyde and hexanal inhibit corrosion of steel by being adsorbed on the metal surface. The better inhibition efficiency of 2-phenylacetaldehyde than that of hexanal could be explained by the quantum parameters.

\section{References}

1. M. Abdullah Dar, Industrial Lubrication and Tribology, 2011, 63, 227-233.

2. W. Focke, N. Nhlapo and E. Vuorinen, Corros. Sci., 2013, 77, 88-96.

3. M. Montemor, "Fostering Green Inhibitors for Corrosion Prevention", in Active Protective Coatings, 2016, 107-137.

4. M. Quraishi and D. Jamal, Corrosion, 2002, 58, 387-391.

5. U. Rammelt, S. Koehler and G. Reinhard, Corros. Sci., 2009, 51, 921-925. 
6. E. Vuorinen and W. Skinner, Brit. Corros. J., 2002, 37, 159-160.

7. N.N. Andreev and Yu.I. Kuznetsov, Russ. Chem. Rev., 2005, 74, no. 8, 685. doi: 10.1070/RC2005v074n08ABEH001162

8. N. N. Andreev and Yu.I. Kuznetsov, Int. J. Corros. Scale Inhib., 2013, 2, no. 1, 39. doi: 10.17675/2305-6894-2013-2-1-039-052

9. E. Chygyrynets' and V. Vorobyova, Chem. Chem. Technol., 2014, 8, 235.

10. V. Vorob'iova, O. Chyhyrynets' and O. Vasyl'kevych, Mater. Sci., 2015, 50, 726. doi: 10.1007/s11003-015-9778-z

11. O.E. Chyhyrynets' and V.I. Vorob'iova, Mater. Sci., 2013, 49, 318 . doi: 10.1007/s11003-013-9617-z

12. O.E. Chyhyrynets, Y.F. Fateev, V.I. Vorobiova and M.I. Skyba, Mater Sci., 2016, 51, 644. doi: 10.1007/s11003-016-9886-4

13. V. Vorobyova, O. Chygyrynets', M. Skiba, I. Kurmakova and O. Bondar, Int. J. Corros. Scale Inhib., 2017, 6, no. 4, 485-503. doi: 10.17675/2305-6894-2017-6-4-8

14. I. Rockenbach, E. Rodrigues, L. Gonzaga, V. Caliari, M. Genovese, A. Gonçalves and R. Fett, Food Chem., 2011, 127, 174-179.

15. A. Ostovari, S. Hoseinieh, M. Peikari, S. Shadizadeh and S. Hashemi, Corros. Sci., 2009, 51, 1935-1949.

16. G. Gece, Corros. Sci., 2008, 50, 2981-2992.

17. S. Garai, S. Garai, P. Jaisankar, J. Singh and A. Elango, Corros. Sci., 2012, 60, $193-$ 204.

18. V. Torres, R. Amado, C. de Sá, T. Fernandez, C. Riehl, A. Torres and E. D'Elia, Corros. Sci., 2011, 53, 2385-2392.

19. L. Guo, S. Kaya, I. Obot, X. Zheng and Y. Qiang, J. Colloid Interface Sci., 2017, 506, 478-485.

20. S. Kaya, B. Tüzün, C. Kaya and I. Obot, J. Taiwan Inst. Chem. Eng., 2016, 58, 528535. 